\title{
Suppression of Orobanche spp. in Tobacco by Native Arbuscular Mycorrhizal Fungi
}

\author{
B. Chandrashekharagowda, P. Jones Nirmalnath*, Shiney Ammanna, \\ P.S. Matiwade and K.S. Jagadeesh
}

Weed Control scheme, Department of Agricultural Microbiology, University of Agricultural Sciences, Dharwad - 580 005, Karnataka, India

*Corresponding author

\section{A B S T R A C T}

\section{Keywords}

Biocontrol, Orobanche,

Tobacco, Arbuscular

mycorrhizal fungal

consortium

Article Info

Accepted:

16 March 2018

Available Online:

10 April 2018
An attempt was made to suppress Orobanche in its subterranean stage of development using native arbuscular mycorrhizal fungi (AMF) on tobacco. In this investigation seven AMF spp. were isolated, grouped and mass multiplied according to their morphological differences, from the Orobanche suppressive soil of a tobacco growing area. Further, these seven native AMF isolates and their consortium, a standard AMF consortium, sugarcane native AMF consortium, recommended dosage of an herbicide and uninoculated controlUIC (absence of AMF spp.) were tested against the Orobanche for their bio-control effect under pot experiment on tobacco plant. The maximum inhibition of Orobanche emergence was observed in the treatments received with standard AMF consortium, native AMF consortium, and sugarcane native AMF consortium. While, the UIC recorded highest number of Orobanche infestation (10.25 weed/pot) followed by Fluchloraline @ 2 per cent (7.5 weed/pot). There was an overall improvement in the physiological and biophysical attributes of tobacco upon AMF colonization. The results indicate that the native AMF isolates could be efficiently used to manage Orobanche in tobacco.

\section{Introduction}

India stands third in the production of tobacco next to China and Brazil. Presently, tobacco is being cultivated in an area of about 4.93 lakh hectares $(0.24$ per cent of total arable land in the country). In India, two different types of tobacco are being produced viz., Flue-Cured Virginia tobacco (FCV) and bidi tobacco. FCV tobacco contributes around 265 million kilograms in an area of 2.17 lakh hectares, in the states of Andhra Pradesh and Karnataka. One of the major causes for yield reduction in tobacco is due to the root parasitic weeds such as Orobanche. Since Orobanche is holoparasitic plant, it establishes directly over the vascular system of the host plant there by drains out water and nutrients from the host, resulting in yield losses to an extent ranging from five to75 per cent depending on the severity of infestation.

The control of Orobanche is difficult because of its high fecundity and asynchronous seed germination. An integrated approach including host plant resistance, cultural practices, and 
chemical and biological treatments is needed for management of this weed infestation.

The seeds of Orobanche will germinate only after induction by a chemical signal exuded from the roots of their host. Recently, it has been demonstrated that certain soil microorganisms like arbuscular mycorrhizal fungi (AMF) inhibiting parasitic weed (Striga) germination (Jones et al., 2014). Studies have also shown that AM fungal colonization is likely to induce resistance to plant parasitism by converting strigolactones into mycorradicin, which is accumulated in mycorrhized roots and thereby reduces availability of strigolactones for Striga to germinate. In this regard, a study was conducted to study the effect of native as well as standard AMF isolates maintained at University of Agricultural Sciences, Dharwad.

\section{Materials and Methods}

An investigation was carried out to isolate native AM fungal isolates from the Orobanche suppressive soils of tobacco growing areas in order to screen them for their ability to suppress Orobanche as well as to promote plant growth under pot culture studies. These experiments were conducted during the year 2015-16 at weed control scheme, Main Agricultural Research Station and Department of Agricultural Microbiology, University of Agricultural Sciences, Dharwad.

Soil samples were collected from Orobanche infested site located at N-16 .40.63.24" latitude; $74^{\circ} .37 .37 .19^{\prime \prime} \mathrm{E}$ longitude, and at an altitude of $585 \mathrm{~m}$ above mean sea level; and Orobanche suppressive sites located at N$16^{\circ} .40 .54 .14$ " latitude; $74^{\circ} .37 .32 .10^{\prime \prime} \mathrm{E}$ longitude, and at an altitude of $586 \mathrm{~m}$ above mean sea level at Nippani of Belgaum district. The soil samples obtained from Orobanche infested soil was used to carry out the pot experiment while native AMF isolates were isolated from Orobanche suppressive soils and were used as inoculants.

Spores isolated from the rhizosphere soil were identified as AM fungi after trap culturing them as described by (Patricia et al., 2009). AM fungal spores were extracted and identified based on morphological features, viz., color, size, wall structure and hyphal attachment as described by Rodrigues and Muthukumar (2009).

Once roots of maize plants start emerging from the stem-tips of the funnels, the contents were transferred to small plastic cups containing sterilized sand: soil (1:1) after confirming the roots for AM colonization. Cultures were maintained and spores were multiplied up to 45 days in cups and later on transferred to plastic pots for the further scaling up and were used in the pot experiment. Based on the characterization sixteen identified native AMF isolates were selected and screened for their ability to suppress Orobanche. The pots were filled with Orobanche infested soil (collected from Nippani of Belgaum district) prior to the sowing. AMF inoculum @ $150 \mathrm{~g} \mathrm{pot}^{-1}$ was mixed thoroughly with the top 10 to $15 \mathrm{~cm}$ of the soil. There were twelve treatments with three replications as follows: UASDAMFT1 to $\mathrm{T} 7$ containing individual isolates of native AMF; T8: UASDAMFT consortium (tobacco native) containing native isolates 1 to 7 ; T9: UASDAMFT consortium (sugarcane native) containing Acaulospora maarowe and Glomus leptotichum, T10: AMF consortium (standard) containing Glomus macrocarpum, Gigaspora margarita and Acaulospora laevis); T11: Orobanche alone as control (UIC) and T12: Fluchloraline@2 per cent.

Number of Orobanche emerged were recorded in each pot. The shoot and root portions of Orobanche plants were separated and oven dried at $60^{\circ} \mathrm{C}$ to constant weight. The dry 
weights were then recorded separately for shoots and roots and average of three were expressed in grams.

The chlorophyll content of tobacco leaves were recorded using single photoelectric analyzing diode (SPAD) meter (SPAD-502 KONICA-Japan). The readings were taken between 10.00 am and $12.00 \mathrm{pm}$ hours of the day.

Measurement of photosynthetic rate, stomatal conductance, rate of transpiration and leaf temperature of tobacco were made on the top fully expanded leaf at different locations by using a portable photosynthesis system (LI6400 LICOR, Nebraska, Lincoln USA). These measurements were made between 10.00 am to 12.00 noon on all the sampling dates.

The data were subjected to analysis following Completely Randomized Design (CRD) as defined by Gomez and Gomez (1984).

\section{Results and Discussion}

The present investigation encompasses isolation, morphological characterization for identification of native AM fungi against Orobanche under pot culture conditions. The results obtained during the investigations are presented below.

Seven AM fungal species were identified during the investigations from the Orobanche suppressive soils. The morphological characteristics of spore are presented in Table 1. Amongnst the AM fungal isolates, Glomus was the predominant genus identified in the study.

The number of Orobanche emerged/pot and their biomass determined is presented in Table 2. Maximum number of weed /pot was observed with UIC (34) followed by Fluchloraline@2 per cent. The lower number of Orobanche was observed in the treatment received UASDAMFT4, AMF consortium (sugarcane native) as seen in Table 2. However, zero number of Orobanche emergences was observed in treatments received AMF consortium (STD), UASDAMFT consortium (tobacco native); suggesting inhibition of germination of the parasitic weed by AM fungi as previously reported by Lendzemo et al., 2001). The seed germination of the Orobanche and Phelipanche species is reduced in the presence of root exudates from pea plants colonized by Glomus mosseae and $G$. intraradices. Reduced germination was due to the effect of the AM fungi and not to the microbial populations potentially present in the soil inoculums (Fernendz et al., 2010). Similarly, reduced Striga number and biomass was also recorded earlier in maize inoculated with AMF (Othira et al., 2012). In tomato, the decrease in parasitism by Phelipanche ramosa upon AM colonization also correlated with a lower induction of germination of seeds of this parasite by the root exudates. Subsequent LCMS analysis showed that the root exudates of colonized plants indeed contained lower amounts of strigolactones (Lopez-Raez et al., 2011).

The AMF consortium (standard), UASDAMFT consortium (tobacco native), UASDAMFS consortium (sugarcane native) and single native AMF isolates UASDAMFT ${ }_{5}$, UASDAMFT $_{2}, \quad$ UASDAMFT $_{6}$ and $\mathrm{UASDAMFT}_{3}$ significantly improved the chlorophyll content compared to the uninoculated plants (Table 3). Abdel and Mohamedin (2000) also observed increased chlorophyll content. This may be due to the increased balanced mineral nutrients like $\mathrm{P}$ and $\mathrm{K}$ content in the leaves of mycorrhizal plants (Giri and Mukerji, 2004). Zuccarini (2007) reported increased concentration of chlorophyll content and total foliar area due to mycorrhization in grapes. 
Table.1 Tentative identification of native AM fungal morpho-types from Orobanche suppressive soils

\begin{tabular}{|c|c|c|c|c|c|c|c|c|}
\hline Isolates & $\begin{array}{l}\text { Code No. of } \\
\text { the isolates }\end{array}$ & Shape & colour & $\begin{array}{c}\text { Spore } \\
\text { mean } \\
\text { Size } \\
(\mu \mathrm{m})\end{array}$ & $\begin{array}{c}\text { Spore wall } \\
\text { thickness } \\
\text { mean } \\
(\mu \mathrm{m})\end{array}$ & $\begin{array}{c}\text { Spore } \\
\text { surface }\end{array}$ & $\begin{array}{c}\text { Size of } \\
\text { Hyphae } \\
\text { mean } \\
(\mu \mathrm{m})\end{array}$ & $\begin{array}{c}\text { AMF } \\
\text { Species }\end{array}$ \\
\hline 1 & UASDAMFT1 & Oval & $\begin{array}{c}\text { Dark } \\
\text { yellow }\end{array}$ & 117.34 & 6.86 & Smooth & ND & $\begin{array}{l}\text { Acaulospora } \\
\text { spp. }\end{array}$ \\
\hline 2 & UASDAMFT2 & Ellipsoidal & Yellow & 109.04 & 8.90 & Smooth & ND & $\begin{array}{l}\text { Glomus } \\
\text { radiata }\end{array}$ \\
\hline 3 & UASDAMFT3 & Ellipsoids & Brown & 129.74 & 9.28 & Rough & ND & $\begin{array}{l}\text { Glomus } \\
\text { mosseae }\end{array}$ \\
\hline 4 & UASDAMFT4 & Round & $\begin{array}{l}\text { Light } \\
\text { Brown }\end{array}$ & 102.44 & 7.06 & Smooth & ND & $\begin{array}{l}\text { Glomus } \\
\text { leptotichum }\end{array}$ \\
\hline 5 & UASDAMFT5 & Oval & $\begin{array}{c}\text { Dark } \\
\text { yellow }\end{array}$ & 126.30 & 8.14 & Granular & 49.12 & $\begin{array}{l}\text { Glomus } \\
\text { fasciculatum }\end{array}$ \\
\hline 6 & UASDAMFT6 & Oval & Brown & 148.40 & 10.2 & Granular & 51.8 & $\begin{array}{l}\text { Glomus } \\
\text { deserticola }\end{array}$ \\
\hline 7 & UASDAMFT7 & Oval & Brown & 109.57 & 8.15 & Smooth & 14.85 & $\begin{array}{l}\text { Glomus } \\
\text { constrictum }\end{array}$ \\
\hline
\end{tabular}

ND; Not determined

Table.2 Impact of AMF on emergence and biomass of Orobanche at 120 DAS

\begin{tabular}{|c|c|c|}
\hline Treatments & $\begin{array}{l}\text { No. of } \\
\text { Orobanche/pot }\end{array}$ & $\begin{array}{l}\text { Total dry } \\
\text { matter }(g)\end{array}$ \\
\hline $\mathrm{T}_{1}-\mathrm{UASDAMIF}$ & 4.33 & 2.50 \\
\hline $\mathrm{T}_{2}-$ UASDAMIF & 0 & - \\
\hline $\mathrm{T}_{3}-\mathrm{UASDAMI}$ & 0 & - \\
\hline $\mathrm{T}_{4}-\mathrm{UASDAMF}$ & 2.66 & 2.42 \\
\hline $\mathbf{T}_{5}-$ UASDAMF & 0 & - \\
\hline $\mathrm{T}_{6}-\mathrm{UASDAMF}$ & 0 & - \\
\hline $\mathrm{T}_{7}-\mathrm{UASDAMF}$ & 3.50 & 2.00 \\
\hline $\begin{array}{l}\text { T } 8 \text { - UASDAMFT consortium } \\
\text { (tobacco native) }\end{array}$ & 0 & - \\
\hline $\begin{array}{l}\text { T9-UASDAMFS consortium } \\
\text { (sugarcane native) }\end{array}$ & 1.44 & 1.20 \\
\hline $\begin{array}{l}\text { T10 - AMF consortium } \\
\text { (standard) }\end{array}$ & 0 & - \\
\hline $\mathbf{T}_{11}-$ Uninoculated control & 10.25 & 19.50 \\
\hline $\begin{array}{l}\mathbf{T}_{12}-\text { Fluchloraline @ } 2 \text { per } \\
\text { cent }\end{array}$ & 7.50 & 14.78 \\
\hline S.Em. \pm & 0.07 & 0.97 \\
\hline C.D. $(1 \%)$ & 0.47 & 3.29 \\
\hline
\end{tabular}

Note: - ; No emergence of Orobanche 
Table.3 Chlorophyll content as influenced by native AM fungal isolates in tobacco (SPAD readings)

\begin{tabular}{|c|}
\hline Treatments \\
\hline $\mathrm{T}_{1}-\mathrm{UASDAMF}$ \\
\hline $\mathrm{T}_{2}-\mathrm{UASDAMF}$ \\
\hline $\mathbf{T}_{3}-$ UASDAMF \\
\hline $\mathrm{T}_{4}-\mathrm{UASDAMF}$ \\
\hline $\mathrm{T}_{5}-\mathrm{UASDAMF}$ \\
\hline $\mathrm{T}_{6}-\mathrm{UASDAMF}$ \\
\hline $\mathrm{T}_{7}-\mathrm{UASDAMF}$ \\
\hline $\begin{array}{l}\mathrm{T}_{8}-\text { UASDAMFT consortium } \\
\text { (tobacco native) }\end{array}$ \\
\hline $\begin{array}{l}\text { T9-UASDAMFS consortium } \\
\text { (sugarcane native) }\end{array}$ \\
\hline $\mathrm{T}_{10}-\mathrm{AMF}$ consortium (standard) \\
\hline $\mathrm{T}_{11}-$ Uninoculated control \\
\hline T12-Fluchloraline @ 2 per cent \\
\hline S.Em. \pm \\
\hline C.D. $(1 \%)$ \\
\hline
\end{tabular}

\begin{tabular}{|l|l|l|}
\hline The chlorophyll content of tobacco plants \\
\hline 60 DAS & 90 DAS & 120 DAS \\
\hline 38.60 & 44.77 & 42.00 \\
\hline 43.17 & 48.07 & 48.00 \\
\hline 42.50 & 47.23 & 43.83 \\
\hline 40.93 & 45.83 & 42.07 \\
\hline 44.33 & 48.93 & 50.37 \\
\hline 43.00 & 47.53 & 45.00 \\
\hline 42.27 & 46.53 & 43.00 \\
\hline 45.97 & 51.53 & 52.93 \\
\hline 45.83 & 51.50 & 51.63 \\
\hline 46.37 & 52.55 & 53.37 \\
\hline 31.17 & 34.62 & 34.07 \\
\hline 33.90 & 39.53 & 37.25 \\
\hline 0.84 & 1.05 & 0.95 \\
\hline 2.49 & 2.97 & 2.67 \\
\hline
\end{tabular}

Table.4 The influence of AMF on biophysical parameters of tobacco plants

\begin{tabular}{|c|c|c|c|c|}
\hline Treatments & $\begin{array}{l}\text { Photosyntheti } \\
\text { c rate ( } \mu \mathrm{mol} \\
\left.\mathrm{m}^{-2} \sec ^{-1}\right)\end{array}$ & $\begin{array}{l}\text { Stomatal } \\
\text { conductance } \\
\left(\mu \mathrm{mol} \mathrm{m}{ }^{-2} \sec ^{-1}\right)\end{array}$ & $\begin{array}{l}\text { Transpiration } \\
\text { rate (mmol m } \\
\left.\text { sec }^{-1}\right)\end{array}$ & $\begin{array}{l}\text { Leaf } \\
\text { temperature } \\
\left({ }^{0} \mathrm{C}\right)\end{array}$ \\
\hline $\mathrm{T}_{1}-$ UASDAMIF & 14.18 & 0.26 & 5.09 & 33.84 \\
\hline $\mathrm{T}_{2}-$ UASDAMIF & 15.23 & 0.30 & 4.04 & 32.63 \\
\hline $\mathrm{T}_{3}-$ UASDAMIF & 14.53 & 0.27 & 4.47 & 33.27 \\
\hline $\mathrm{T}_{4}-$ UASDAMIF & 14.36 & 0.27 & 4.63 & 33.46 \\
\hline $\mathrm{T}_{5}-$ UASDAMIF & 15.47 & 0.32 & 3.88 & 31.75 \\
\hline $\mathrm{T}_{6}-\mathrm{UASDAMF}$ & 15.05 & 0.28 & 4.18 & 32.66 \\
\hline $\mathrm{T}_{7}-$ UASDAMIF & 14.44 & 0.27 & 4.55 & 33.28 \\
\hline $\begin{array}{l}\text { T8 - UASDAMFT consortium } \\
\text { (tobacco native) }\end{array}$ & 20.75 & 0.36 & 3.18 & 30.52 \\
\hline $\begin{array}{l}\text { T9- UASDAMFS consortium } \\
\text { (sugarcane native) }\end{array}$ & 20.38 & 0.34 & 3.24 & 31.42 \\
\hline $\mathrm{T}_{10}-\mathrm{AMF}$ consortium (standard) & 22.72 & 0.37 & 3.02 & 28.79 \\
\hline $\mathbf{T}_{11}-$ Uninoculated control & 11.10 & 0.20 & 5.32 & 36.27 \\
\hline $\mathrm{T}_{12}$-Fluchloraline @ 2 per cent & 11.95 & 0.22 & 5.22 & 34.57 \\
\hline S.Em. \pm & 0.66 & 0.01 & 0.09 & 0.56 \\
\hline C.D. $(1 \%)$ & 2.61 & 0.04 & 0.38 & 2.25 \\
\hline
\end{tabular}


Further, they have also noticed an improvement in the chlorophyll contents (chlorophyll a, b and total chlorophyll).

The data on biophysical parameters of tobacco plants as influenced by different AM fungal isolates are presented in Table 4. These parameters also showed maximum values, where AMF was inoculated.

This is in agreement with the reports of Selvaraj and Chellapan (2006), who also reported an increased photosynthetic activity in the leaves of Prosopis julifera inoculated with G. fasciculatum.

These results suggest that AM fungal colonization likely induces resistance to plant parasitism by reducing the exudation of strigolactones from the host roots.

The outcome of the present investigations indicated that AMF consortium (standard), UASDAMFT consortium (tobacco native), UASDAMFS consortium (sugarcane native) along with native AMF isolates can be used to suppress Orobanche, simultaneously influencing the stimulation of physiological and biophysical attributes of tobacco.

Further field trials are warranted to ascertain the positive effects exhibited by the native arbuscular mycorrhizal fungal isolates on tobacco and suppression of Orobanche.

\section{Acknowledgement}

The authors are thankful to all the staff members of Weed control scheme and Institute of Agricultural research on Climate Change, MARS, University of Agricultural Science, Dharwad, Karnataka for their valuable support and guidance for the present study. This study was funded by Rastriya Krishi Vikas Yojane (RKVY), Government of Karnataka.

\section{References}

Abdel, F. G. and Mohamedin, A. H., 2000, Interactions between a vesiculararbuscular mycorrhizal fungus and streptomyces and their effects on sorghum plants. Biol. Fert. Soils, 32: 401-409.

Fernandez, N., Aparicio, M., Garci Garrido A, J, M., Ocampo, J, A. and Rubiales, D., 2010, Colonisation of field pea roots by arbuscular mycorrhizal fungi reduces Orobanche and Phelipanche spp. seed germination. Weed Res., 50: 262-268.

Giri, B. and Mukerji, K., 2004, Mycorrhizal inoculant alleviates salt stress in Sesbania aegyptiaca and Sesbania grandiflora under field conditions: evidence for reduced sodium and improved magnesium uptake. Mycorrhiza, 14: 307-312.

Gomez, K. A. and Gomez, A. A., 1984, Statistical Procedures for Agricultural Research, $2^{\text {nd }}$ Edition, A WileyInternational Sciences Publ., New York (USA), pp. 125-130.

Jones, N. P., Madhura, A. S., Prashant, S. S., Ramesh, B., Jagadeesh, K. S. and Asha A. N., 2014, Evaluation of arbuscular mycorrhizal fungi for suppression of Striga hermonthica, a parasitic weed in sorghum. Paper presented In: Biennial conference on Emerging Challenges in Weed Management, DWSR, Jabalpur, $\mathrm{p}$. 227.

Lendzemo, L. M. and Kuyper, T. W., 2001, Effects of arbuscular mycorrhizal fungi on damage by Striga hermonthica on two contrasting cultivars of sorghum. Agric. Ecosyst. Environ., 87: 29-35.

Lopez-Raez, J. A., Charnikhova, T., Fernandez, I., Bouwmeester, $\mathrm{H}$. and Pozo, M. J., 2011, Arbuscular mycorrhizal symbiosis decreases strigolactones production in tomato. $J$. Plant Physiol, 168: 294-297. 
Othira, J. O., Omolo, J. O., Wachira, F. N. and Onek, L. A., 2012, Effectiveness of arbuscular mycorrhizal fungi in protection of maize (Zea mays L.) against witch weed (Striga hermonthica Del Benth) infestation. J. Agric. Biotech. Sustainable Dev., 4 (3): 37-44.

Patricia L. L., Sturmer, S. L. and Siqueira, J. O., 2009, Occurrence and diversity of arbuscular mycorrhizal fungi in trap cultures from soils under different land use systems in the amazon. Brazil. Brazilian J. Microbiol., 40: 111-121.
Rodrigues, B. F. and Muthukumar, T., 2009, Arbucular Mycorrhizae of Goa-A manual of identification protocols.

Selvaraj, T. and Chellappan, P., 2006, Arbuscular mycorrhizae: a diverse personality. J. Central European Agric., 7 (2): 58-65.

Zuccarini, P., 2007, Mycorrhizal infection ameliorates chlorophyll content and nutrient uptake of lettuce exposed to saline irrigation. Plant Soil Environ, 53 (7): 283-289.

\section{How to cite this article:}

Chandrashekharagowda, B., P. Jones Nirmalnath, Shiney Ammanna, P.S. Matiwade and Jagadeesh, K.S. 2018. Suppression of Orobanche spp. in Tobacco by Native Arbuscular Mycorrhizal Fungi. Int.J.Curr.Microbiol.App.Sci. 7(04): 1890-1896. doi: https://doi.org/10.20546/ijcmas.2018.704.216 